\title{
Intimate Partner Survivors' Help-Seeking and Protection Efforts: A Person-Oriented Analysis
}

\author{
Paula S. Nurius ${ }^{1}$, Rebecca J. Macy ${ }^{2}$, ljeoma Nwabuzor ${ }^{2}$, and Victoria L. Holt ${ }^{1}$ \\ ${ }^{1}$ University of Washington, Seattle \\ ${ }^{2}$ University of North Carolina, Chapel Hill
}

\section{Abstract}

Domestic violence advocates and researchers advocate for a survivor-centered approach for assisting women experiencing intimate partner violence (IPV), with individualized safety plans and services; yet little empirical work has been done to determine IPV survivors' specific combinations of vulnerabilities and assets that might inform such an approach. Using latent profile analysis of a cohort of 448 survivors, five distinct subgroups were previously identified in terms of biopsychosocial asset and vulnerability profiles. The purpose of the current study was to apply person-oriented methodology for survivor-centered investigation of differences in help-seeking and protective actions according to subgroup membership within this cohort. Though not differing demographically, the subgroups were found to differ significantly and meaningfully in their patterns of IPV help-seeking and protective actions. Thus, reliance on population-aggregate linear relationships between IPV exposure and safety efforts may risk overlooking important variation by vulnerability and asset profile, and knowledge of distinct clusters among functioning profiles may help with understanding of survivors' coping strategies. The authors outline service-need considerations across the subgroups and provide guidance for targeted outreach, locating IPV survivors and matching services to their needs.

\section{Keywords}

battered women; domestic violence; intervention/treatment; legal intervention

Over the course of the domestic violence movement, safety services have been developed by community-based providers, including advocacy, counseling, support group, and shelter. A recent review of the domestic violence services literature, as well as domestic violence coalition service guidelines, showed general agreement about how these safety services should be delivered to partner violence survivors (Macy, Giattina, Sangster, Crosby, \& Montijo 2009). Even with such agreement, this research also showed that services should be delivered in a way that attends to survivors' unique and varied needs. Likewise, Goodman and Epstein (2008) recently called for a renewal of the survivor-centered approach in domestic violence service delivery. They and others argue that such an individualized service philosophy differs from perspectives that postulate universal approaches (e.g., mandatory arrest policies for intimate partner violence [IPV] perpetrators) work best in protecting IPV survivors from future violence (Briere \& Jordan, 2004; Lindhorst, Nurius, \&

\footnotetext{
(c) The Author(s) 2011
}

Corresponding Author Paula S. Nurius, University of Washington, 4101 15th Ave NE, Seattle, WA 98105 nurius@u.washington.edu.

Declaration of Conflicting Interests

The authors declared that they had no conflicts of interests with respect to their authorship or the publication of this article. 
Macy, 2005; Roberts \& Roberts, 2002). Those calling for survivor-centered approaches posit that survivors not only have different experiences of IPV but also have different vulnerabilities and needs related to these experiences of violence. In a related vein, IPV survivors have varying assets and resources that may buffer the effects of their IPV experiences and that they can draw on in coping and seeking help and safety (Carlson, McNutt, Choi, \& Rose, 2002).

Considerable theoretical and substantive work exists describing this survivor-centered approach (for a review, see Macy et al., 2009); yet far less empirical work has been conducted to determine IPV survivors' individualized combinations of vulnerabilities and assets. IPV research to date has predominantly used variable-oriented methodologies to focus on linear trends that characterize samples as a whole (i.e., IPV prevalence and associations of IPV with other factors). This body of work has provided critical information about IPV phenomena. However, these methods generally are not designed to systematically test the extent to which there is heterogeneity among IPV survivors that may affect the accuracy or generalizability of aggregate-based sample findings. Thus, little is known about how differing combinations of vulnerabilities and assets shape IPV survivors' help-seeking or protective actions. Even less is known about how to screen for or target interventions to different combinations of co-occurring vulnerabilities and assets that influence survivors' capacities to seek help and use protective strategies.

To address this empirical knowledge gap, the current study applies person-oriented methodology for survivor-centered investigation of differences in help-seeking and protective actions. Specifically, this investigation builds on prior research that tested for patterned clusters among IPV survivors on the basis of biopsychosocial factors that (a) are commonly associated with IPV and (b) are theorized to affect survivors' stress responding and coping (Nurius and Macy, 2009). Derived from a sample of 448 IPV survivors, these prior findings determined five distinct subgroups of women with significantly differing profiles. The current study extends these prior findings to investigate the extent to which and in what ways these groups of IPV survivors with significantly different profiles of psychosocial vulnerabilities and assets differ in their defensive coping actions, operationalized here as formal service help-seeking and protective actions. We provide a discussion of person-oriented methods followed by summary of these prior findings as a foundation for the current study.

\section{Person-Oriented and Variable-Oriented Methods}

Variable-oriented methods assume samples are sufficiently homogeneous to allow study findings to be generalized across populations. These methods typically rely on analytic techniques, such as ANOVA and regression, applied to aggregate data obtained from samples to explain relationships among measured variables. Variable-oriented approaches offer powerful analytic options and provide important understandings about the prevalence and factors associated with IPV, how risk factors combine to increase risk of exposure or damage from abuse, and how interventions are associated with desired and unanticipated changes (e.g., Kilpatrick, Acierno, Resnick, Saunders, \& Best, 1997; McFarlane, Groff, O'Brien, \& Watson, 2006). Thus, such research provides a context within which to explore person-oriented research questions regarding heterogeneity among samples of IPV survivors.

Person-oriented methods are based on the idea that diverse patterns of relationships among factors may be embedded within samples or populations; thus, the use of aggregated analytic approaches risks obscuring group differences that may be theoretically and clinically meaningful (von Eye \& Bogat, 2006). Rather than assuming homogeneity within a given 
sample or population on characteristics important to a given question (such as risk factors believed to bear substantially on outcomes), person-oriented approaches use analytic tools to test for statistical differences in meaningful patterns among these characteristics. Rather than single case analysis, these approaches are testing for the existence of subgroups within samples. Results can illuminate nuances in prior findings. Macy, Nurius, and Norris (2007), for example, found that different types of relationships between victimization histories and recent drinking habits were important contributors in detecting subgroups of sexual assault victims. Person-oriented statistical methods, such as latent profile or latent class analysis, enable examination of relationships among a multivariate array of factors to determine whether the nature of these interrelationships reveals that some individuals are more like one another and different enough from others to constitute significantly distinct subgroups. If established, these subgroups can then be examined as to the implications of their differences (e.g., Kohl \& Macy, 2008).

Recent research in the domain of violence against women reflects this concern with heterogeneity, applying person-oriented approaches to test for subgroups whose divergent needs may hold practice and policy implications (Bogat, Levendosky, \& von Eye, 2005; Hughes \& Huth-Bocks, 2007; Nurius \& Macy, 2008). This body of work indicates the value of person-oriented methods as well as the value of combining person- and variable-oriented methods to advance the field's understanding of different dimensions of heterogeneity among IPV survivors. One arena in which person-oriented methods may hold special value is offering empirically based evidence toward informing survivor-centered intervention approaches for tailored, adaptive interventions that calibrate the forms and levels of services that are best suited to different subgroup needs (Collins, Murphy, \& Bierman, 2004). Findings from the present investigation hold potential for such service planning, for example, through assessing profile factors to ascertain service fit and/or referral priorities.

\section{Survivor Multivariate Profiles}

Latent profile analysis was previously used in testing for subgroups in the current sample (Nurius and Macy, 2009). Five groups of survivors were determined to be statistically distinct and substantively meaningful, and each group was named to reflect their distinct combination of biopsychosocial assets and vulnerabilities: (a) multiple resources (MR), (b) struggling with depression (SD), (c) vulnerable-supported (VS), (d) vulnerable-depressed (VD), and (e) severe functioning impairment (SFI). Figure 1 displays each group's empirical profile on the biopsychosocial factors used to test for subgroups within the sample. These biopsychosocial factors included the following: injuries from the IPV index incident, physical functioning, depression, survivors' appraisals of their vulnerability relative to their violent partner, and both positive and negative social relationships. Group mean scores on the biopsy-chosocial measures are standardized in Figure 1 to allow portrayal of levels above or below the sample mean. We next summarize the substantive rationale for inclusion of each of the biopsychosocial factors and hypotheses relative to survivors' coping actions.

\section{Vulnerability Appraisals}

IPV is a significant stressor and threat to women's well-being, with variability in level of felt stress and coping responding. Survivors' appraisals of their vulnerability to their partners (e.g., susceptibility to physical and psychological danger, loss of power and control in a relationship, feeling trapped) are an important dimension for understanding survivors' experiences of IPV as well as their coping process (Smith, Smith, \& Earp, 1999). This premise is consistent with stress and coping theory, which holds that individuals can react differently to the same stressor as a function of their interpretations of that stressor (Lazarus $\&$ Folkman, 1984). Findings have been consistent with theory, demonstrating associations 
between survivors' appraisals of IPV and their biopsychosocial needs, coping efforts, and willingness to seek help (Macy, Nurius, Kernic, \& Holt, 2005; Pape \& Arias, 2000; Smith, Thornton, DeVellis, Earp, \& Coker, 2002). Thus, we anticipated that higher vulnerability appraisals may serve to galvanize survivors' outreach to formal service providers. However, we also anticipated that these relationships may be shaped by other contextual factors. For example, the relationships between vulnerability and help seeking may be muted in the presence of greater positive social support if survivors are able to avail themselves of informal sources of help.

\section{Depression}

Depression repeatedly has been shown to be elevated with abuse and negatively related to both adaptive coping and use of coping resources such as social support (Carlson et al., 2002; Hathaway et al., 2000; Kramer, Lorenzon, \& Mueller; 2004; Porcerelli et al., 2003; Zlotnick, Johnson, \& Kohn, 2006). Therefore, depression symptoms are likely to adversely affect women's ability to take self-protective actions. However, when depression is embedded in differing clusters of biopsychosocial functioning, its relationship to subsequent coping would be expected to reflect more variability than bivariate findings alone have revealed. In the present study, we theorized that depression may function synergistically with vulnerability appraisals, such that elevated levels of both would be associated with greater impairment and service needs than elevated depression alone.

\section{Injury}

Survivors often experience multiple IPV-related injuries following an incident of abuse (Sheridan \& Nash, 2007). In general, the higher the severity of violence resulting in injury, the greater the IPV victim's help-seeking and safety planning actions (Goodkind, Sullivan, \& Bybee, 2004). What is not yet assessed, however, is how comparable levels of IPV-related injury do (or do not) combine with other factors to affect patterns of help-seeking and protections actions among IPV survivors. We anticipated that high levels of injury would tend to trigger higher levels of service involvement, such as emergency medical care as well as higher levels of defensive coping (i.e., use of protective actions). However, the response of women with lower levels of injury may depend substantially on their surrounding functioning profile (e.g., physical functioning, positive social relationships).

\section{Physical Health Functioning}

Distinct from injury, the vast research on IPV and health shows that survivors are more likely than women who have not been abused to experience report physical health problems, including chronic pain, gynecological and reproductive health problems, gastrointestinal disorders, and sleep disturbances (Caldwell \& Redeker, 2005; Campbell, 2002; Coker, 2007; Macy, Ferron, \& Crosby, 2009). Moreover, IPV survivors use health care services at least as often as women who are not violence survivors (Plichta, 2007), and some research shows that survivors use health care more than women who are not violence survivors, including prescriptions and hospital admissions (Coker, Derrick, Lumpkin, Aldrich, \& Oldendick, 2000; Kernic, Wolf, \& Holt, 2000; Tolman \& Rosen, 2001). Inclusion of recent health combines with injury status in assessing how current physical functional capacity combines with psychosocial vulnerabilities and assets to affect help-seeking and protective actions.

\section{Social Support}

Survivors' social support is typically understood as buffering the impact of partner violence on physical and mental health and improving coping, and therefore, such support is usually regarded as a protective factor (Carlson et al., 2002; Coker, Watkins, Smith, \& Brandt, 
2003). However, not all social relationships offer protective potential, as is evidenced by the negative effects of socially strained relations on IPV survivors (Nurius et al., 2003). Thus, negative and positive social relationships provide different information, with different implications for coping, such as buffering versus exacerbating stress and facilitating or eroding protective options. We anticipated that negative social relationships would be of equal importance to positive relationships in profile configurations, with effects in the above-noted directions.

\section{Subgroup Profiles}

A full and detailed discussion of the methodological procedures used to determine these groups can be found elsewhere (Nurius and Macy, 2009). Here, we provide a brief overview of the profile group findings, illustrated in Figure 1.

The first profile group $(n=68)$, referred to as multiple resources, was distinct in terms of comparatively better physical health, less difficulty with depression, lower vulnerability appraisals, and high positive social support. Women with the second profile, struggling with depression $(n=69)$, were distinguished by their relatively high levels of depression combined with lower vulnerability appraisals. The third profile group, vulnerable-supported $(n=58)$, was characterized by elevated vulnerability appraisals relative to the first two groups but with relatively high positive social relationships and relatively less difficulty with physical health and depression. The fourth profile, vulnerable-depressed $(n=160)$, reported the second highest level of vulnerability appraisals as well as higher than average depression. As with SD women, this group reported lower positive and higher negative relations relative to MR and VS women. The fifth profile, severe functioning impairment ( $n$ =93), exhibited a consistent pattern of high levels of injury, depression, vulnerability appraisals, and negative social relations in addition to lower levels of both physical functioning and positive social support.

Although women with the greatest level of impairment reported highest levels of violence exposure, there was not a consistent trend across the survivor profile groups. Women with the highest and lowest levels of violence exposure-severe functioning impaired and MR groups, respectively—exhibited virtually mirror opposite biopsychosocial profiles. However, there was considerable variability among the remaining groups, with women who had experienced comparable levels of violence manifesting significantly different biopsychosocial profiles. Thus, although screening for abuse on the basis of violence exposure is important to identify women with potentially unmet safety and support needs (Bonomi, Holt, Thompson, \& Martin, 2005), exposure details may not map well onto the kinds of support services that survivors need or seek. The current study allows the next step, linking associations between differing vulnerability and asset profiles in the aftermath of intimate partner assault to patterns of help-seeking and protective actions.

\section{Method}

\section{Sample and Recruitment}

Participants were 448 adult (aged 18 or greater) female victims of abuse by a male intimate partner that resulted in a police-reported incident (not necessarily by the survivor) or the filing of a protection order in Seattle, Washington (Wolf, Holt, Kernic, \& Rivara, 2000). Stratified random sampling was used based on police-reported incidents and protection order filings within a 14 month period. The incident of abuse that led to the police report and/or the filing of the protection order constituted the index episode of abuse that led to the subject's recruitment. Nearly half the sample $(n=209)$ reported both that the police were called at the index event and that they filed for a protection order because of this event. The 
index event constituted the point of access to a diverse sample of IPV survivors at relatively comparable points in their current violence exposure (e.g., sufficient to trigger police reporting and/or protection order filing).

The University of Washington's Human Subjects Review Committee approved study protocols. Eligible study participants were telephoned approximately 1 month after the index incident and asked to participate. Of the 742 women eligible for the study, 124 (16.7\%) refused to participate, $62(8.4 \%)$ agreed but did not complete interviews, $108(14.6 \%)$ could not be contacted, and 448 (60.4\%) were enrolled. Participants and nonparticipants were found to be similar on age, marital status, proportion having a child with the abuser, type of offense reported to the police, and proportion injured at the index incident. Participants were more likely than nonparticipants to have obtained protection orders (56.5\% vs. $41.8 \%)$ and less likely to be living with the abuser at the time of the index incident $(26.7 \%$ vs. $36.4 \%)$. Participants were given the option of completing an interviewer-administered telephone interview or a self-administered mailed copy of the survey. Eighty-one percent chose the telephone interview, and no significant differences were detected as a function of method. Participants' ages ranged from 18 to 70 years $(M=32.01, S D=9.46)$. In terms of race and ethnicity, $54.3 \%$ of the participants described themselves as White, $21.5 \%$ as African American, $7.2 \%$ as Asian/Pacific Islander, $4.3 \%$ as Native American/Alaska Native, 25\% as Hispanic/Latino, and $5.9 \%$ as biracial or a combination of the race/ ethnicity categories. Education attained ranged from eighth grade or less (2.2\%), some high school (HS; 9.2\%), HS graduate/General Educational Development (24.6\%), post-HS training but not college (7.8\%), some college (37.5\%), college graduate (15.4\%), to advanced/graduate degree (3.3\%). Participants' occupational status at the time of the index incident ranged from being employed full time (48.9\%), employed part time (12.3\%), attending school (3.8\%), both attending school and employed (9\%), to not employed outside the home (25.3\%). Less than $1 \%$ of the sample reported either being self-employed or disabled. Household income ranged from less than US $\$ 15,000$ per year (43.9\%), US\$15,000-US\$19,999 (11.8\%), US\$20,000US\$24,999 (8.3\%), US\$25,000-US\$34,999 (14.5\%), US\$35,000-US\$49,999 (12\%), US $\$ 50,000$-US $\$ 69,000(4.9 \%)$, to US $\$ 70,000$ and above (4.7\%). Less than $5 \%$ of the participants were not U.S. citizens.

\section{Measures}

Data on survivors' help-seeking and protection actions after the index incident were collected through survey questionnaires that followed a structured format using several wellevaluated measures described below. The psychometric properties of measures used to test for the profiles that distinguish the subgroups are fully described in the original report (Nurius and Macy, 2009). Table 1 provides brief overviews of these profiling measures.

\section{Help Seeking}

Participants were asked about a range of formal help-seeking efforts on the following: domestic violence services (four items, e.g., shelter or housing, support groups, advocacy, and domestic violence counseling), legal services (six items, e.g., assistance with divorce, custody, or separation; assistance with police charge; assistance with protection order; assistance with prosecution; assistance with crime victim's compensation; and assistance with support enforcement or paternity action), health care (four items, e.g., health care focused on services as a result of partner violence: receiving first aid at scene of incident from paramedics, seeking out a health care provider in an office or clinic, visiting an emergency room, and staying overnight in a hospital), economic assistance (two items, e.g., receiving welfare, food stamps, or social security, and food bank services), substance abuse treatment (three items, e.g., drug treatment, alcohol treatment, and Alcohol Anonymous or Narcotics Anonymous), counseling services (two items, e.g., private counseling and Al- 
Anon), and religious-spiritual services (one item, e.g., sought help from religious or spiritual organizations). These items were developed in conjunction with the research advisory board members and reflect the range of human services available and used by IPV survivors in the metropolitan area where the study was conducted.

For all types of help seeking except health care (see description below), participants were instructed to report on help-seeking efforts since the index event, distinguishing if they received a specific service, attempted to access the service but did not receive the service, or did not attempt to access the service. Overall, there were too few reports of unsuccessful attempts to access services to allow group difference testing. Thus, percentages of help seeking per service category were based on the proportion of respondents who attempted to access one or more service per category (e.g., one or more of the four specific domestic violence services), irrespective of whether they successfully accessed these services or not (reported in Table 2). Help seeking was also calculated as a sum of all efforts across service categories, with the following values: $2=$ accessed, $1=$ attempted without access, or $0=$ no attempt. Health care help seeking focused on services sought as a result of the partner violence index incident only; therefore, only yes $=1$ and no $=0$ responses were available and summed. These data were used for tests reported in Table 3.

\section{Protection Actions}

Protective actions were assessed in terms of whether the woman reported she left/ended the abusive relationship following the abuse incident or obtained a protection order. Protection orders can vary as to what conditions are specified (e.g., requiring treatment) and prohibit the abusive person from harassing or contacting the protection order petitioner (the woman experiencing IPV) and limit contact with minor children. Temporary protection orders are in place for 14 days, at which time the court holds a full order hearing. At this hearing, the court decides whether to extend the protection order for a year or longer. The resultant orders are termed permanent protection orders and require the petitioner to attend the hearing and request change to a permanent order. All items were asked in yes/no formats and coded $0=$ no and $1=y e s$.

\section{Results}

\section{Help Seeking}

Percentages of participants who sought one or more forms of help across each service category are presented in Table 2 . Tests of profile group differences as to the level of services sought within these service categories is presented in Table 3. These analyses are based on mean scores of the summated values for each service category.

To avoid risk of an inflated overall type I error rate from multiple univariate tests (Stevens, 1996), multivariate ANOVA was first used to provide an omnibus test for statistically significant differences among the five profile groups across the help-seeking action categories. Wilks's Lambda was used to test the multivariate null hypothesis that there would be no differences among the groups on their help-seeking efforts immediately following the index event; this analysis showed significant overall differences with a value of $3.96(p<.001)$.

ANOVAs were applied to determine which profile groups did and did not significantly differ from one another on each type of help-seeking efforts (see Table 3). These tests reveal significant mean differences across the five profile groups for seeking domestic violence, legal, health, and substance abuse services; differences did not achieve significance on economic, counseling, and religious/spiritual help seeking. Tukey post hoc tests were 
applied to specific group-to-group comparisons on services for ANOVA tests showed overall group differences. Overall, the SFI group sought significantly more help in terms of domestic violence, legal, health, and substance abuse services relative to most of the other groups. In contrast, the MR group showed significantly less help seeking for many types of services relative to the other groups. Specifically, the SD profile group showed significantly greater legal and health help-seeking compared with the MR group, the VS group reported significantly greater legal help seeking than the MR group, and the VD group showed significantly greater domestic violence services help seeking than the MR group. The SD group also reported greater health help seeking relative to the VS group.

\section{Protection Actions}

Chi-square analyses tested for significant differences among the profile groups on protection variables - whether participants had obtained a temporary protection order, whether they had obtained a permanent protection order, whether they had left or ended the relationships with their abusive partner, and number of times previously left this partner. These tests demonstrated significant differences for each of these actions (see Table 4). Overall trends in these findings were similar to the help-seeking findings discussed above, with the MR group engaging in far fewer protection actions and the SFI group engaging in more of these actions. Also notable is that the SD, VD, and VS groups also were engaged in a striking number of these protective actions.

\section{Demographics}

It is noteworthy that although we investigated demographic characteristics - including age $\left(18-24,25-34,35-44,45+; \chi^{2}=14.09, p=.30\right)$, race and ethnicity (African American, Asian/Pacific Islander, White, Native American, Hispanic, Other; $\chi^{2}=16.92, p=.44$ ), income (<US\$15K, US\$15K-US\$19,999, US\$20K-US\$24,999, US\$25K-US\$34,999, US $\$ 35 \mathrm{~K}-\mathrm{US} \$ 49,999$, US $\left.\$ 50 \mathrm{KUS} \$ 69,999,>\mathrm{US} \$ 70 \mathrm{~K} ; \chi^{2}=17.51, p=.83\right)$, education $(<\mathrm{HS}$, HS, some college/post HS, college graduate, advanced degree; $\chi^{2}=16.72, p=.40$ ), employment (full time, part time, employed student, unemployed student, neither employed nor in school; $\chi^{2}=17.33, p=.14$ ), and having health insurance (private, Medicaid/ Medicare, other, none; $\chi^{2}=4.54, p=.81$ ) -in relation to the profile groups, none achieved significance. Similarly, the profile groups were not statistically significantly different on marital status (married, separated/divorced, dating/boyfriend, ex-boyfriend; $\chi^{2}=13.11, p=$. 26 ) or the duration of the relationship ( $\$ 6$ months, 7-12 months, 13-24 months, 2-5 years, $>5$ years; $\chi^{2}=16.73, p=.40$ ).

\section{Discussion}

Extending a previous study that established five statistically distinct and substantively meaningful subgroups of IPV survivors, the current study examined each group in relation to the members' coping in terms of formal help-seeking and protective actions. Results revealed that the groups differed significantly on help-seeking efforts pertaining to domestic violence, legal, health, and substance abuse services. In addition, the groups differed on obtaining temporary and permanent protection orders and leaving (or ending) the relationship with the abusive partner. These results imply that different combinations of vulnerabilities and resources shape IPV survivors' active coping efforts to manage IPV, even with comparable forms and levels of violence exposure involved.

As reported in the prior paper, women with the most severe impairment (SFI group) reported the highest levels of IPV exposure both before and at the target incident (Nurius and Macy, 2009). Beyond that, however, there was more comparability than difference across the profile groups as to the levels of violence experience. Our findings demonstrate meaningful 
structure within heterogeneity among IPV survivors in biopsychosocial functioning as well as distinct patterns in the help-seeking efforts and protection actions across these subgroups, to which we now turn.

\section{Help-Seeking and Protective Action Group Distinctions}

MR-The participants in the MR group sought fewer services, and fewer of these women engaged in protection actions after the index incident relative to the participants in the other groups. These findings are consistent with prior variable-oriented research with this same sample of women (Nurius and Macy, 2009) as well as the IPV help-seeking research generally (Coker et al., 2000; Henning \& Klesges, 2002; Hutchison \& Hirschel, 1998). Overall, this research has shown that IPV survivors who experience lower levels of and less severe IPV are less likely to seek formal help relative to survivors who experienced high levels and severe IPV. Nonetheless, the current person-oriented findings from the MR group reveal important nuances not evident previously.

Specifically, the MR group was previously found to report exposure to IPV (psychological, physical, and sexual) at the index incident and physical abuse during the prior year that was similar to that of the SD and VS groups (Nurius and Macy, 2009). The levels of violence at the index event were sufficiently serious to evoke legal involvement (police and/or court order). Therefore, we conclude that the descriptive nature of violence exposure alone may not account for the differing arrays of help-seeking and protection actions of the women in the MR, SD, and VS groups. The low level of vulnerability appraisals by MR women indicate lesser psychological impact of the violence experienced. This, combined with their high positive and low negative social relationships, may position them for greater reliance on informal supports and greater buffering of the stress associated with their IPV experiences.

From this study, it is clear that many of the women fitting the MR profile do come to the attention of the legal system. This finding, in conjunction with previous findings showing that longer duration IPV is associated with increased legal help seeking (Duterte et al., 2008), implies that efforts should be made by the legal system and domestic violence services to provide early outreach interventions to women fitting this profile. Such outreach interventions may help reduce the risk of escalated IPV and trauma development for these women. Consistent with domestic violence advocacy approaches (see, e.g., Maine Coalition to End Domestic Violence, 2005), we recommend that these early interventions include safety-planning services that seek to reinforce supportive relationships, paired with education to understand IPV and prevent or decrease appraisals of powerlessness and entrapment.

VS-The VS group was less likely to seek help for legal and health services when compared to the SFI and SD groups. However, the VS group accessed significantly more legal services than the MR group. In addition, the VS group took greater protection actions compared to MR and SD groups.

When compared to MR group, VS women had comparable physical functioning, limited injuries at incident, and very favorable positive-to-negative social relationship resources. However, the average depression level of VS women indicated mild depression, which makes this group of participants substantively distinct from the MR group. In addition to depression, this group also endorsed higher levels of appraisals of vulnerability to their abuser and experienced greater psychological abuse over the prior year relative to the MR group profiles (Nurius and Macy, 2009). 
Thus, the VS group's high psychological vulnerability suggests this group is more likely to feel threatened by their abusers in comparison to the MR group. Consistent with prior research (Goodkind et al., 2004; Macy et al., 2005), these finding show that higher severity of violence and the greater vulnerability appraisals of the VS group may serve to galvanize help-seeking as well as protective actions. VS women, for example, reported the greatest proportion of prior efforts to leave the relationship—-more than $30 \%$ with six or more previous efforts.

It is noteworthy that the VS group shows elevated depression symptoms relative to the MR group, along with higher vulnerability appraisals, increased help seeking, and protective actions. Though it seems that depression might dampen help-seeking as well as protective actions (as we theorize for the SD group, discussed below), the findings from this group suggest a more complex relationship between depression, vulnerability appraisals, and active coping actions. Though the current study does not allow for further investigation of these relationships, we encourage attention to the relationships and interactions between depression, vulnerability appraisals, and protective actions in future research efforts.

Similarly to the MR group, women fitting the VS profile may be most likely to be found when they access legal services related to their abuse. Although they have strong personal support systems, the needs of these women should not be underestimated at this entry point, with particular attention paid to encouragement of treatment of depression if applicable and to furthering their understanding of the dynamics of IPV to decrease their vulnerability to their abusers.

SD-The SD group was more likely to use legal and health services than the MR group and used more health services than the VS group. Given that SD women reported more injuries at index incident, lower physical health functioning, and less favorable positive-to-negative social relations than both MR and VS groups, it is not surprising that SD participants were more likely to seek health care services relative to the MR and VS groups (Coker et al., 2000; Tolman \& Rosen, 2001).

The finding that nearly a third of the participants in this group sought health care indicates that health care providers should be prepared to screen for IPV and be ready with information about how and where survivors can access safety help (Plichta, 2007). McFarlane and colleagues (2006) found a reduction in violence and an increase in safety actions among survivors who received abuse assessment and a wallet-sized referral card with safety planning information and information about sources of safety services in the context of health care services (i.e., shelter, legal, counseling, and police). Such a health care-based intervention may be especially useful for survivors whose biopsychosocial profiles match this SD group.

Although the VS group did not differ significantly from the SD group in terms of IPV exposure, these groups were notably different in their biopsy-chosocial profiles. The SD group reported lower vulnerability than the VS group; however, the SD group reported more injuries at index incident, lower physical functioning, and less favorable positive-to-negative social relations (Nurius and Macy, 2009). When compared to VS, it appears depression may play a critical part in SD's lower levels of persisted protection actions. SD women's actions reflect an immediate response (e.g., via temporary protection orders) but less persistence as reflected in few permanent protection orders and fewer prior attempts to leave the relationship (e.g., 23\% left more than twice before compared to 53\% for vulnerable but supported women). It is also possible that because the $\mathrm{SD}$ group feels less susceptible to physical and/or psychological danger in their intimate relationships, they are less likely to 
feel the need to escape. Furthermore, depression may lead this group of women into a mental state (i.e., withdrawal) that keeps them from addressing their stressful event directly.

As discussed earlier, depression may have an especially erosive effect on survivors' health and well-being, and depression is one of the most common mental health problems among IPV survivors (Campbell, 2002; Golding, 1999; Tolman \& Wang, 2005). Given that a high level of depression is a defining characteristic of this group, the pairing of mental health with safety interventions may be especially relevant for survivors who have biopsychosocial profiles similar to this group. Research shows that IPV survivors are less likely to report depressive symptoms with the cessation of IPV (Golding, 1999; Kernic, Holt, Stoner, Wolf, \& Rivara, 2003). Such findings suggest a reciprocal and dynamic relationship between violence and depression. Thus, the combination of safety and mental health services is likely critical for women struggling with both partner violence and depression.

Although there are few rigorously researched practices for IPV survivors that pair mental health and safety interventions, the emerging area of trauma-informed services for women with mental illness may provide guidance to providers working with survivors who profiles are similar to the SD group. According to the principles of trauma-informed service, integrated care for survivors should address trauma and the co-occurring mental health problem concurrently (Elliott, Bjelajac, Fallot, Markoff, \& Reed, 2005). Trauma-informed practice also emphasizes inclusion, respect for individuality and diversity, and women's autonomy, which are consistent with the philosophies of the domestic violence movement. Although a full discussion of this treatment approach is beyond the scope of our discussion here, we recommend trauma-informed services as one possible intervention approach for the women in this group as well as the other groups of participants with depression (i.e., VD and SFI) and other mental health needs.

VD-The proportion of VD women who accessed domestic violence services was higher than all other groups, except SFI. The women in the VD group had exceptionally high levels of appraised vulnerability that involved deeply ingrained, enduring experiences of vulnerability, loss of power and control, and entrapment that carry serious risks for future victimization risk and deepening trauma development (Smith, Edwards, \& DeVellis, 1998). This finding is especially striking, considering how active this group was in terms of helpseeking as well as protection actions. Seventy-five percent of participants in this group sought legal help, 36\% economic help, and 30\% counseling services. In addition, $70 \%$ of the participants in this group obtained a permanent protection order, and more than half left the relationship with their abusive partner after the index event, compared to $51 \%$ and $38 \%$, respectively, for struggling-depression women. As discussed earlier, these clustered findings suggest the power of women's vulnerability appraisals in relation to their partners in galvanizing active coping and protective actions, even in the face of considerable depression symptoms.

The multidimensional biopsychosocial needs of the VD group underscore the importance of comprehensive services that combine safety planning with mental and physical health services for women with a similar biopsychosocial profile (Elliott et al., 2005; Riger, Raja, \& Camacho, 2002). Similar to SD, the women fitting the VD biopsychosocial profile were more likely than the MR and VS groups to need coordinated help with their physical health, mental health, and safety (Nurius and Macy, 2009). Thus, the biopsychosocial profile of this VD group suggests that services that focus on one problem are likely to be less effective for IPV survivors with this need profile than services that attend to women's multiple needs in combination. Although these women may be galvanized to seek help and to leave their abusive relationships, health, human, and legal service providers must be prepared to meet these women's needs with a coordinate and comprehensive response. 
SFI-This group accessed the greatest number of services by far. They used significantly more domestic violence services than all other groups; accessed more legal services than MR, SD, and VS; received more health services than MR, VS, and VD; and utilized more substance abuse treatment services than MR and VD. The SFI group also took greater protection actions relative to the other groups, with three quarters obtaining permanent protection orders, nearly two thirds leaving the abusive relationships after the index event, and $24 \%$ reporting six or more prior efforts to leave.

The SFI group findings correspond to previously mentioned studies suggesting that the higher the severity of violence a woman experiences, the greater her likelihood of taking help-seeking and safety planning actions. Our prior study showed that the SFI group experienced the highest level of IPV at the index event and in the year prior to the index event (Nurius and Macy, 2009). Nevertheless, the findings from the current study showing that this group of participants engaged in high levels of help seeking, as well as protective actions, is promising given their high levels of need.

On its face, the considerable and complex set of needs seen in this profile group suggest a group of women who may be overwhelmed and unable to cope with the serious IPV they are experiencing. Instead, the help-seeking and protection findings associated with this group reveal that this group of survivors is engaged in active planning and outreach efforts. These findings are consistent with what others have previously described as the survivor theory, in which women are able to engage their strengths and resources in the face of even horrific abuse to find help and end the violence in their lives (Gondolf, 1998).

The findings for this group show these participants were seeking help across the range of health, human services, and legal services investigated here. Thus, we encourage health, human, and legal service providers - regardless of their specialties - to be well prepared to assess and respond to the needs of violence survivors' whose biopsychosocial profiles match these findings. Health, human service, and legal providers should always be ready with useful information about how and where survivors can access emergency shelter and safety services (Plichta, 2007; Robinson \& Spilsbury, 2008). We also echo our earlier recommendations that providers are prepared to attend to women's multiple needs in combination and by offering a comprehensive service response.

The positive relationship between SFI's use of services, their protection actions, and their high levels of IPV victimization suggest that service providers should offer services aimed at the immediate safety of women with these biopsychosocial profiles, such as domestic violence crisis response and shelter services. The extent of IPV that the women in this profile group experienced is worrisome in terms of the women's safety and well-being. Furthermore, women with these sets of needs and lack of assets may especially be in need of formal services, given their lack of access to supportive, positive social relationships with their friends and family.

\section{Limitations}

Sampling is a perennial challenge in violence research. The current sample overlaps helpseeking samples such as those drawn from shelters or other providers serving IPV survivors. The current sample benefits, however, from inclusion of women often not easily accessedwomen whose only help seeking was a 911 call in a crisis or for whom others initiated this call and police involvement. The majority of the current sample had not previously obtained services from violence specialists. Although this sampling may offer a wide measure of representativeness, the findings may not be fully generalize to IPV survivors who belong to certain groups (e.g., immigrant communities) or live in particular geographical areas (e.g., 
rural), where interventions such as police involvement or legal actions may be less likely with incidents of IPV.

Overall, the women who chose not to participate in this study were similar to the women who did participate, with two notable exceptions: Nonpartici-pants were less likely to have taken out protection orders at the point of interview contact and were more likely to have remained living with the offending intimate partner. Such differences highlight the importance, yet difficulty, of accessing the full range of IPV survivors. We cannot ascertain, for example, whether nonparticipants would be adequately captured within the five groups established here or may represent an additional group. Although the sample was relatively diverse and the groups did not significantly differ as to racial composition, the small number of specific groups of women across race and ethnicities hampers assessment of how racial and cultural factors may play a role in understanding biopsychosocial heterogeneity.

\section{Next Steps in Investigating Group Structures}

Although every effort was made in the original research to assess the most parsimonious and best fitting profile model, it is premature to look to these groupings as a classification system or a complete typology. Subsequent research is needed to assess the replicability of multivariate structures (i.e., groups) across samples with the same biopsychosocial constructs as well as determine whether factors such as local context may yield somewhat unique subgroups that were not evident in the current sample. In addition, findings are predicated on theoretical foundations that inform the selection of variables to use in the search for subgroups. Latent factor tools, such as latent profile analysis, allow examination of how risk and protective factors may configure in importantly distinct ways across individuals. Changing the factors that are used in investigation of heterogeneity may well hold substantial implications for the nature of the relationships among the factors in question and, thus, the resultant subgroup structure.

Demographic variables can be influential in many aspects of survivors' exposure to, experience of, and coping with IPV. Lack of differences between the profile groups on the demographics measured here should not be interpreted as indicating lack of relevance of these factors to help-seeking or to any given biopsychosocial variable. Prior work has indicated, for example, disparities in vulnerabilities and assets on the basis of race as well as significant associations of socioeconomic indicators with help seeking, for example, of legal, economic, and counseling services (Bent-Goodley, 2005; Macy et al., 2005). Rather, the current findings indicate fairly even distribution of demographic characteristics across the patterned relationships among the biopsychosocial variables. Person-oriented methodologies may stimulate new ways to examine relationships of structural indicators, such as demographic characteristics, to experiences of violence against women that provide a complement to single factor and variable-oriented approaches.

The emphasis in this study was on multilevel factors theorized to affect coping actions in the context of recent IPV. Other factors would be relevant for different kinds of research questions. In addition to testing generalizability of these particular biopsychsocial profiles, we encourage future research efforts to apply structure searching analysis to capture additional theorized phenomena, such as context, history, and variations in personal meaning (Bogat et al., 2005; Waldrop \& Resick, 2004).

\section{Conclusion}

These findings argue for the complementary value of person-oriented methodologies in the study of IPV, facilitating examination of heterogeneity. This investigation shows that reliance on population-aggregate linear relationships between IPV exposure, psychosocial 
profile, and safety efforts risk overlooking significant variation. The current findings, for example, demonstrate that distinct clusters among functioning profiles have important implications for understanding survivors' coping strategies-here operationalized through help-seeking and protective efforts.

Findings such as these extend the field's preparedness to more systematically assess variation as well as to consider implications of patterns within variation-here reflected in terms of subgroups-for service planning. We have outlined service-need considerations for each of the five identified profile groups. Our findings also provide guidance about where to find certain IPV survivors in terms of help-seeking patterns (e.g., in hospitals/clinics, financial aid offices, legal services) and how to think about what services may best match their needs. Given that the majority of survivors, in this and other samples, do not access domestic violence-specialized services, targeted outreach is essential. Our findings reinforce the importance of routine screening for IPV exposure in health and justice service settings. Although this study was not designed to produce screening criteria, findings do point to depression, feelings of vulnerability, and social isolation as useful indicators for screening development and to guide referral and case management decisions.

Coping with IPV is an ongoing, dynamic process. Consistent with prior research (e.g., Arriaga \& Capezza, 2005; Lerner \& Kennedy, 2000; Waldrop \& Resick, 2004), these findings support the importance of understanding and tailoring service supports to optimize relevance to survivors' needs. Degree of violence exposure constitutes an important predictor of need-but one that is not universal and is conditioned by factors such as vulnerabilities and assets. Further efforts to think at the interface relative to how copingrelated variables come together in differing ways promises to increase our effectiveness in responding to diverse needs and priorities.

\section{Acknowledgments}

We appreciate the contribution of Marsha Wolf in the procurement of the original grant and of Dr. Frederick Rivara and Dr. Mary Kernic in the conduct of the original study as well as their support for the present article.

Funding

The authors disclosed that they received the following support for their research and/or authorship of this article: This project was supported by Grant 1 R01 DA11151, "Protection of Women: Health and Justice Outcomes," from the Centers for Disease Control and Prevention, National Institutes of Health, and National Institute of Justice, as part of the Interagency Consortium on Violence Against Women and Family Violence Research and Grant 5 T32 MH200010, "Mental Health Prevention Research Training Program."

\section{Biography}

Paula S. Nurius, PhD, MSW, MA, is a professor and director of the NIMH-funded Prevention Research Training Program at the University of Washington School of Social Work. Current research addresses coping responses to violence, risk and protective factors impinging on coping and protective action, and preventive interventions to strengthen resistance and resilience. Projects include gender-based violence, multi-form violence effects on high risk youth transitioning from adolescence to early adulthood, and disparities stemming from cumulative stress.

Rebecca J. Macy, PhD, MSW, is an associate professor at the School of Social Work at the University of North Carolina at Chapel Hill. She is a licensed social worker with practice experience in community mental health with violence survivors. Her program of research focuses on developing and testing interventions that promote violence survivors' health and 
well-being, as well as prevent their revictimization. Dr. Macy has also written about cognitive therapy techniques.

Ijeoma Nwabuzor is a doctoral student at the University of North Carolina at Chapel Hill. She earned a BA in psychology from Spelman College, and graduated with an MA in social work from the University of Pennsylvania. Her research interests include the co-occurrence of domestic violence and child abuse/neglect, child welfare, domestic violence, and AfricanAmerican children and families.

Victoria L. Holt, PhD, MPH, is a professor of epidemiology in the University of Washington School of Public Health, also affiliated with the Program in Epidemiology, Fred Hutchinson Cancer Research Center. Dr. Holt's primary research interests include reproductive epidemiology and intimate partner violence. Recent projects concern the associations between violence during pregnancy and adverse infant outcomes, the effect of protection orders on future intimate partner violence, and the impact of the justice system response to partner violence on the risk of subsequent violence and injury.

\section{References}

Arriaga XB, Capezza NM. Targets of partner violence: The importance of understanding coping trajectories. Journal of Interpersonal Violence. 2005; 21:89-99. [PubMed: 15618565]

Bent-Goodley T. Culture and domestic violence. Journal of Interpersonal Violence. 2005; 20:195-203. [PubMed: 15601792]

Bogat GA, Levendosky AA, von Eye A. The future of research on intimate partner violence: Personoriented and variable-oriented perspectives. American Journal of Community Psychology. 2005; 36:49-70. [PubMed: 16134044]

Bonomi AE, Holt VL, Thompson RS, Martin DP. Ascertainment of intimate partner violence in women seeking legal protection. American Journal of Preventive Medicine. 2005; 28:52-58. [PubMed: 15626555]

Briere J, Jordan CE. Violence against women: Outcome complexity and implications for assessment and treatment. Journal of Interpersonal Violence. 2004; 19:1252-1276. [PubMed: 15534329]

Caldwell BA, Redeker N. Sleep and trauma: An overview. Issues in Mental Health Nursing. 2005; 26:721-738. [PubMed: 16126648]

Campbell J. Health consequences of intimate partner violence. Lancet. 2002; 359:1331-1336. [PubMed: 11965295]

Carlson BE, McNutt L, Choi DY, Rose IM. Intimate partner abuse and mental health. Violence Against Women. 2002; 8:720-745.

Coker AL. Does physical intimate partner violence affect sexual health? A systematic review. Trauma, Violence \& Abuse. 2007; 8:149-177.

Coker AL, Derrick C, Lumpkin JL, Aldrich TE, Oldendick R. Help-seeking for intimate partner violence and forced sex in South Carolina. American Journal of Preventive Medicine. 2000; 19:316-320. [PubMed: 11064237]

Coker AL, Watkins KW, Smith PH, Brandt HM. Social support reduces the impact of partner violence on health: Application of structural equation models. Preventive Medicine. 2003; 37:259-267. [PubMed: 12914832]

Collins LM, Murphy SA, Bierman KL. A conceptual framework for adaptive preventive interventions. Prevention Science. 2004; 5:185-196. [PubMed: 15470938]

Cooper P, Osborn M, Gath D, Feggetter G. Evaluation of modified self-report measure of social adjustment. British Journal of Psychiatry. 1982; 141:68-75. [PubMed: 7116075]

Duterte EE, Bonomi AE, Kernic MA, Schiff MA, Thompson RS, Rivara FP. Correlates of medical and legal help seeking among women reporting intimate partner violence. Journal of Women's Health. 2008; 17(1):85-95. 
Elliott D, Bjelajac P, Fallot R, Markoff L, Reed BG. Trauma-informed or trauma-denied: Principles and implementation of trauma-informed services for women. Journal of Community Psychology. 2005; 33:461-477.

Golding JM. Intimate partner violence as a risk factor for mental disorders: A meta-analysis. Journal of Family Violence. 1999; 14:99-132.

Gondolf, EW. Assessing woman battering in mental health services. Sage; Thousand Oaks, CA: 1998.

Goodkind J, Sullivan CM, Bybee D. A contextual analysis of battered women's safety planning. Violence Against Women. 2004; 10:514-533.

Goodman, LA.; Epstein, D. Listening to battered women: A survivor-centered approach to advocacy, mental health and justice. American Psychological Association; Washington, DC: 2008.

Hathaway J, Mucci L, Silverman J, Brooks D, Mathews R, Pavlos C. Health status and health care use of Massachusetts women reporting partner abuse. American Journal of Preventive Medicine. 2000; 19:302-307. [PubMed: 11064235]

Henning KR, Klesges LM. Utilization of counseling and supportive services by female victims of domestic abuse. Violence and Victims. 2002; 17:623-636. [PubMed: 12477102]

Hughes HM, Huth-Bocks AC. Variations in parenting stress in African-American battered women: Implications for children's adjustment and family intervention. European Psychologist. 2007; 12:62-71.

Hutchison IW, Hirschel JD. Abused women: Help-seeking strategies and police utilization. Violence Against Women. 1998; 4:436-546.

Kernic MA, Holt VL, Stoner JA, Wolf ME, Rivara FP. Resolution of depression among victims of intimate partner violence: Is cessation of violence enough? Violence and Victims. 2003; 18:115129. [PubMed: 12816399]

Kernic MA, Wolf M, Holt V. Rates and relative risk of hospital admission among women in violent intimate partner relationships. American Journal of Public Health. 2000; 90:1416-1420. [PubMed: 10983199]

Kilpatrick DG, Acierno R, Resnick HS, Saunders BE, Best CL. A 2-year longitudinal analysis of the relationship between violent assault and substance use in women. Journal of Consulting and Clinical Psychology. 1997; 65:834-846. [PubMed: 9337502]

Kohl PL, Macy RJ. Profiles of victimized women among the child welfare population: Implications for targeted child welfare policy and practices. Journal of Family Violence. 2008; 23:57-68.

Kramer A, Lorenzon D, Mueller G. Prevalence of intimate partner violence and health implications for women using emergency departments and primary care clinics. Women's Health Issues. 2004; 14:19-29. [PubMed: 15001185]

Lazarus, RS.; Folkman, S. Stress, appraisal, and coping. Springer; New York: 1984.

Lerner CF, Kennedy LT. Stay-leave decision making in battered women: Trauma, coping, and selfefficacy. Cognitive Therapy and Research. 2000; 24:215-232.

Lindhorst T, Nurius P, Macy RJ. Contextualized assessment with battered women: Strategic safety planning to cope with multiple harms. Journal of Social Work Education. 2005; 41:331-352. [PubMed: 18167523]

Macy RJ, Ferron J, Crosby C. Partner violence and survivors' chronic health: Informing social work practice. Social Work. 2009; 54(1):29-43. [PubMed: 19205255]

Macy RJ, Giattina M, Sangster TH, Crosby C, Montijo NJ. Domestic violence and sexual assault services: Inside the black box. Aggression and Violent Behavior. 2009; 14:359-373.

Macy RJ, Nurius PS, Kernic MA, Holt VL. Battered women's profiles associated with service helpseeking efforts: Illuminating opportunities for intervention. Social Work Research. 2005; 29:137150.

Macy RJ, Nurius PS, Norris J. Latent profiles among sexual assault victims: Highlighting implications for defensive coping and resistance. Journal of Interpersonal Violence. 2007; 22:543-565. [PubMed: 17429022]

Maine Coalition to End Domestic Violence. Service standards \& definitions for Maine Coalition to End Domestic Violence member projects. 2005 (Available from the author, 170 Park Street, Bangor, ME 04401). 
McFarlane JM, Groff JY, O'Brien JA, Watson K. Secondary prevention of intimate partner violence: A randomized control trial. Nursing Research. 2006; 55(1):52-61. [PubMed: 16439929]

Nurius PS, Macy RJ. Heterogeneity among violence exposed women: Applying person-oriented research methods. Journal of Interpersonal Violence. 2008; 23:389-415. [PubMed: 18245574]

Nurius PS, Macy RJ. Person-oriented methods in partner violence research: Distinct biopsychosocial profiles among battered women. Journal of Interpersonal Violence. 2009 Prepublished November 6, 2009; DOI: 10.1177/0886260509340541.

Nurius PS, Macy RJ, Bhuyan R, Holt VL, Kernic MA, Rivara FP. Contextualizing depression and physical functioning in battered women: Adding vulnerability and resources to the analysis. Journal of Interpersonal Violence. 2003; 18:1411-1431. [PubMed: 14678614]

Pape KT, Arias I. The role of perceptions and attributions in battered women's intentions to permanently end their violent relationships. Cognitive Therapy and Research. 2000; 24:201-214.

Plichta SB. Interactions between victims of intimate partner violence against women and the healthcare system: Policy and practice implications. Trauma, Violence \& Abuse. 2007; 8:226-239.

Porcerelli JH, Cogan R, West PP, Rose EA, Lambrecht D, Wilson KE, et al. Violent victimization of women and men: Physical and psychiatric symptoms. Journal of American Board of Family Practice. 2003; 16:32-39.

Radloff LS. The CES-D scale: A self-report depression scale for research in the general population. Applied Psychological Measurement. 1977; 1:385-401.

Riger S, Raja S, Camacho J. The radiating impact of intimate partner violence. Journal of Interpersonal Violence. 2002; 17:184-205.

Roberts, AR.; Roberts, BS. A comprehensive model for crisis intervention with battered women and their children.. In: Roberts, AR., editor. Handbook of domestic violence intervention strategies. Oxford; New York: 2002. p. 365-395.

Robinson L, Spilsbury K. Systematic review of the perceptions and experiences of accessing health services by adult victims of domestic violence. Health and Social Care in the Community. 2008; 16:16-30. [PubMed: 18181812]

Sheridan DJ, Nash KR. Acute injury patterns of intimate partner violence victims. Trauma, Violence \& Abuse. 2007; 8:281-289.

Smith PH, Earp JAL, DeVellis R. Measuring battering: Development of the women's experience with battering (WEB) scale. Women's Health: Research on Gender, Behavior, and Policy. 1995; 1:273288.

Smith PH, Smith JB, Earp JAL. Beyond the measurement trap: A reconstructed reconceptualization of woman battering. Psychology of Women Quarterly. 1999; 23:177-193.

Smith PH, Thornton GE, DeVellis R, Earp J, Coker AL. A population-based study of the prevalence and distinctiveness of battering, physical assault, and sexual assault in intimate relationships. Violence Against Women. 2002; 8:1208-1232.

Smith, SP.; Edwards, G.; DeVellis, R. Intimate partner violence: Prevalence, co-occurrence, and health consequences. American Public Health Association; Washington, DC: 1998.

Stevens, J. Applied multivariate statistics for the social science. 3rd ed.. Lawrence Erlbaum; Mahwah, NJ: 1996.

Tolman RM, Rosen D. Domestic violence in the lives of women receiving welfare. Violence Against Women. 2001; 7:141-158.

Tolman RM, Wang H. Domestic violence and women's employment: Fixed effects models of three waves of women's employment study data. American Journal of Community Psychology. 2005; 36:147-158. [PubMed: 16134051]

von Eye A, Bogat GA. Person-oriented and variable-oriented research: Concepts, results, and development. Merrill-Palmer Quarterly. 2006; 52:390-420.

Waldrop AE, Resick PA. Coping among adult female victims of domestic violence. Journal of Family Violence. 2004; 19:291-302.

Ware JE, Kosinski M, Keller SD. A 12-item short-form health survey: Construction of scales and preliminary tests of reliability and validity. Medical Care. 1996; 34:220-233. [PubMed: 8628042] 
Wolf ME, Holt VL, Kernic MA, Rivara FP. Who gets protection orders for intimate partner violence? American Journal of Preventive Medicine. 2000; 19:286-291. [PubMed: 11064233]

Zlotnick C, Johnson D, Kohn R. Intimate partner violence and long-term psychosocial functioning in a national sample of American women. Journal of Interpersonal Violence. 2006; 21:262-275.

[PubMed: 16368765] 


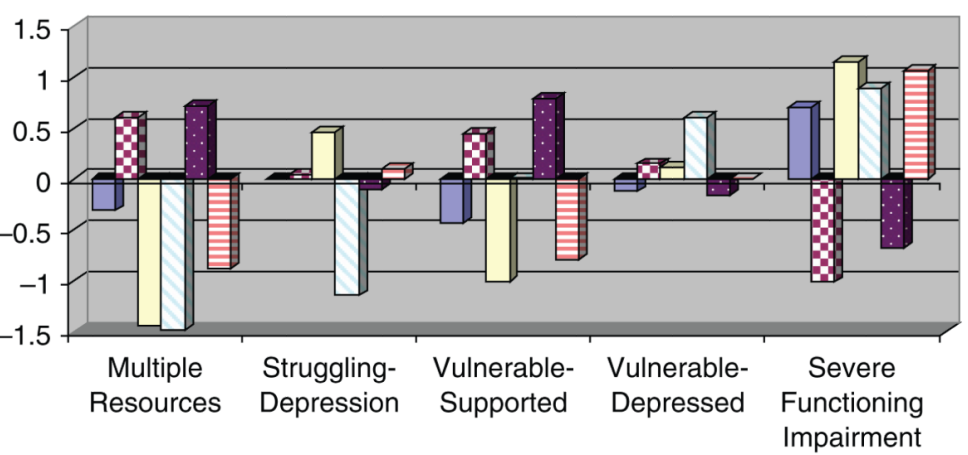

\begin{tabular}{lll}
\hline Incident Injuries & $\square$ Physical Health & $\square$ Depression \\
$\square$ Vulnerability Appraisals & $\square$ Positive Social & $\square$ Negative Social
\end{tabular}

Figure 1.

Standardized profile group means for biopsychosocial variables Note: Reprinted from Nurius and Macy (2009). 


\section{Table 1}

\section{Summary of Measures Used to Test for Subgroups}

\begin{tabular}{ll}
\hline Measure & Key Features \\
\hline Vulnerability appraisals & Women's Experience With Battering Scale (Smith, Earp, \& DeVellis, 1995) \\
& 10 items, 6-point Likert-type scale, alpha = .94 \\
& Center for Epidemiological Studies of Depression Scale (Radloff, 1977) \\
Depression & 20 items, 4-point Likert-type scale, alpha = .95 \\
& Social Adjustment Scale (Cooper, Osborn, Gath, \& Feggetter, 1982) \\
Social relations & 5-point Likert-type scales; seven items of positive relations, alpha = .80; nine items of negative relations, alpha = .69 \\
& Physical Health Component of the SF-12 (Ware, Kosinski, \& Keller, 1996) \\
Physical functioning & $\begin{array}{l}\text { Eight items; included 6-point, 5-point, and 3-point Likert-type scales and yes/no items; alpha = .81, } R^{2} \text { with SF-36 = } \\
\text { 0.91 } \\
\text { Summation of yes/no (1/0) participant responses to list of injuries (e.g., pain, bruises/swelling, cuts/bleeding, broken } \\
\text { bone, internal injuries, loss of consciousness) }\end{array}$ \\
\hline
\end{tabular}

J Interpers Violence. Author manuscript; available in PMC 2014 March 26. 


\section{Table 2}

Percentage of Participants Who Sought Help (Combining Accessed and Attempted-Not Accessed) Across Service Categories for Overall Sample and Profile Subgroups

\begin{tabular}{lccccccc}
\hline Service Categories & Domestic Violence & Legal & Health & Economic & Substance Treatment & Counseling & Religious/Spiritual \\
\hline Sample $(N=448)$ & $38.0 \%$ & $66.0 \%$ & $17.0 \%$ & $32.0 \%$ & $9.0 \%$ & $31.0 \%$ & $7.0 \%$ \\
Subgroups & & & & & & & \\
Multiple resources & $7.0 \%$ & $39.7 \%$ & $4.5 \%$ & $27.9 \%$ & $5.9 \%$ & $17.6 \%$ & $1.5 \%$ \\
Struggling with depression & $29.0 \%$ & $62.3 \%$ & $29.0 \%$ & $34.8 \%$ & $8.7 \%$ & $36.2 \%$ & $8.7 \%$ \\
Vulnerable-supported & $34.5 \%$ & $63.8 \%$ & $3.4 \%$ & $31.0 \%$ & $10.3 \%$ & $29.3 \%$ & $1.7 \%$ \\
Vulnerable-depressed & $40.6 \%$ & $75.0 \%$ & $12.5 \%$ & $31.3 \%$ & $5.0 \%$ & $31.3 \%$ & $6.9 \%$ \\
Severe functioning impairment & $58.1 \%$ & $74.2 \%$ & $32.6 \%$ & $36.6 \%$ & $19.4 \%$ & $38.7 \%$ & $11.8 \%$ \\
Number of services assessed & 4 & 6 & 4 & 2 & 3 & 2 & 1 \\
\hline
\end{tabular}


Table 3

MANOVA, Profile Group ANOVAs, and Between-Group Tests on Number of Services Sought After Partner Violence Incident

\begin{tabular}{|c|c|c|c|c|c|c|}
\hline & Multiple Resources (MR) & $\begin{array}{l}\text { Struggling } \\
\text { With } \\
\text { Depression } \\
\text { (SD) }\end{array}$ & Vulnerable-Supported (VS) & Vulnerable-Depressed (VD) & $\begin{array}{c}\text { Severe } \\
\text { Functioning } \\
\text { Impairment } \\
\text { (SFI) }\end{array}$ & $\begin{array}{l}\text { Tukey } \\
\text { Post Hoc } \\
\text { Between- } \\
\text { Group } \\
\text { Tests }\end{array}$ \\
\hline ANOVAs & $M(S D)$ & $M(S D)$ & $M(S D)$ & $M(S D)$ & $M(S D)$ & \\
\hline $\begin{array}{l}\text { Domestic } \\
\text { violence } \\
\text { services, } \\
F(4,441) \\
= \\
42.93^{* * *}\end{array}$ & $0.26(0.80)$ & $0.77(1.38)$ & $0.93(1.55)$ & $1.43(2.12)$ & $2.20(2.51)$ & $\begin{array}{l}\text { VD > } \\
\text { MR SFI } \\
>\text { MR, } \\
\text { SD, VS, } \\
\text { VD }\end{array}$ \\
\hline $\begin{array}{l}\text { Legal } \\
\text { services, } \\
F(4,441) \\
= \\
63.51^{* * *}\end{array}$ & $1.18(1.67)$ & $2.38(2.61)$ & $2.40(2.49)$ & $2.99(2.48)$ & $3.66(2.99)$ & $\begin{array}{l}\mathrm{SD}>\mathrm{MR} \\
\mathrm{VS}>\mathrm{MR} \\
\mathrm{SFI}> \\
\mathrm{MR}, \mathrm{SD}, \\
\mathrm{VS}\end{array}$ \\
\hline $\begin{array}{l}\text { Health } \\
\text { services, } \\
F(4,441) \\
=4.55^{* * *}\end{array}$ & $0.04(0.21)$ & $0.42(0.74)$ & $0.35(0.18)$ & $0.20(0.60)$ & $0.59(1.02)$ & $\begin{array}{l}\mathrm{SD}> \\
\mathrm{MR}, \mathrm{VS} \\
\mathrm{SFI}> \\
\mathrm{MR}, \mathrm{VS}, \\
\mathrm{VD}\end{array}$ \\
\hline $\begin{array}{l}\text { Economic } \\
\text { services, } \\
F(4,441) \\
=0.38\end{array}$ & $0.59(0.98)$ & $0.70(1.00)$ & $0.69(1.11)$ & $0.71(1.16)$ & $0.78(1.10)$ & \\
\hline $\begin{array}{l}\text { Substance } \\
\text { treatment, } \\
F(4,441) \\
=3.35^{* * *}\end{array}$ & $0.18(0.83)$ & $0.23(0.81)$ & $0.24(0.76)$ & $0.09(0.42)$ & $0.58(1.34)$ & $\begin{array}{l}\text { SFI > } \\
\text { MR, VD }\end{array}$ \\
\hline $\begin{array}{l}\text { Counseling } \\
\text { services, } \\
F(4,441) \\
=2.11\end{array}$ & $0.34(0.77)$ & $0.71(1.00)$ & $0.53(0.86)$ & $0.61(0.91)$ & $0.74(0.97)$ & \\
\hline $\begin{array}{l}\text { Religious- } \\
\text { spiritual } \\
\text { services, } \\
F(4,441) \\
=2.00\end{array}$ & $0.03(0.24)$ & $0.16(0.53)$ & $0.03(0.26)$ & $0.14(0.51)$ & $0.20(0.58)$ & \\
\hline
\end{tabular}

Note: Overall MANOVA of group differences across all services; Wilks's Lambda $=.78, F(28,1569.84)=3.96 * * *$. Tukey results are significant from $p<.05$ to $p<.000$.

$* * *$ $p \leq .001$. 
Table 4

Profile Group Differences for Temporary Protection Orders, Permanent Protection Orders, and Leaving Relationships

\begin{tabular}{|c|c|c|c|c|c|c|}
\hline Protection Actions & $\begin{array}{l}\text { Multiple } \\
\text { Resources }(n \\
=68)\end{array}$ & $\begin{array}{l}\text { Struggling } \\
\text { With } \\
\text { Depression ( } n \\
=69)\end{array}$ & $\begin{array}{c}\text { Vulnerable- } \\
\text { Supported }(n= \\
58)\end{array}$ & $\begin{array}{c}\text { Vulnerable- } \\
\text { Depressed }(n= \\
160)\end{array}$ & $\begin{array}{c}\text { Severe } \\
\text { Functioning } \\
\text { Impairment }(n \\
=93)\end{array}$ & $\chi^{2}$ \\
\hline Temporary protection order & $24(41 \%)$ & $36(56 \%)$ & $33(41 \%)$ & $91(64 \%)$ & $51(63 \%)$ & $12.31^{* *}$ \\
\hline Permanent protection order & $26(39 \%)$ & $35(51 \%)$ & $39(67 \%)$ & $110(70 \%)$ & $68(74 \%)$ & $28.82^{* * *}$ \\
\hline Left relationship after index & $19(28 \%)$ & $26(38 \%)$ & $17(30 \%)$ & $83(53 \%)$ & $60(65 \%)$ & $31.85^{* * *}$ \\
\hline $\begin{array}{l}\text { Number of prior attempts to } \\
\text { leave }\end{array}$ & & & & & & $30.47^{* *}$ \\
\hline Never & $25.9 \%$ & $24.1 \%$ & $14.0 \%$ & $18.0 \%$ & $15.7 \%$ & \\
\hline 1-2 times & $48.1 \%$ & $53.4 \%$ & $32.6 \%$ & $34.4 \%$ & $30.0 \%$ & \\
\hline $3-5$ times & $18.5 \%$ & $12.1 \%$ & $23.3 \%$ & $32.0 \%$ & $30.0 \%$ & \\
\hline 6-10 times & $1.9 \%$ & $6.9 \%$ & $18.6 \%$ & $10.2 \%$ & $14.3 \%$ & \\
\hline$>10$ times & $5.6 \%$ & $3.4 \%$ & $11.6 \%$ & $5.5 \%$ & $10.0 \%$ & \\
\hline
\end{tabular}

